\title{
Implementasi Sistem Informasi Bergerak Untuk Penguatan Surveilans Gizi di Puskesmas Banguntapan II Kabupaten Bantul
}

\author{
L.N. Harnaningrum ${ }^{1}$, Sigit Anggoro ${ }^{2}$, Adiyuda Prayitna ${ }^{3}$, Syamsumin Kurnia Dewi ${ }^{4}$ \\ ${ }^{1,2,3}$ STMIK AKAKOM Yogyakarta \\ J1 Raya Janti 143, Yogyakarta 55198 \\ ${ }^{4}$ Akademi Fisioterapi "YAB" Yogyakarta \\ J1. Ring Road Selatan, Giwangan, Umbulharjo, Yogyakarta, Indonesia \\ Email : ${ }^{1}$ ningrum@akakom.ac.id, ${ }^{2}$ sigitanggoro@akakom.ac.id, \\ 3yudha_pr@akakom.ac.id, ${ }^{4}$ dikdewik@yahoo.com
}

\begin{abstract}
Severe malnutrition still exists as a health problem in District of Bantul. A preliminary study at Puskesmas Banguntapan II shows that severe malnutrition rate is still high and the nutrition surveillance is not done optimally. Surveillance activities, like: data collection, data compilation, data analysis and interpretation, and data report are carried out manually. This study is geared to build an application based on short message service to strengthen the nutrition surveillance. This study was conducted on March-November 2013 at Puskesmas Banguntapan II. Subjects were midwives and village health promoters in this area. The application that was built consist of interface set in the user's cellular phone and server. Data were saved in the puskesmas's database for the report need. This application is expected to increase the speed, accuracy, completeness and sustainability of data on nutrition surveillance, especially for child severe malnutrition detection, so an adequate treatment can be carried out promptly.
\end{abstract}

Keywords: mobile information system, nutrition surveillance, severe malnutrition.

\begin{abstract}
Abstrak. Gizi buruk saat ini masih menjadi masalah kesehatan di Kabupaten Bantul. Studi pendahuluan di Puskesmas Banguntapan II menunjukkan bahwa selain angka gizi buruk yang masih tinggi, surveilans gizi juga belum berjalan optimal. Sebagian kegiatan surveilans berupa: pengumpulan data, pengolahan dan penyajian data, analisis dan interpretasi data, serta pelaporan, masih dilakukan secara manual. Oleh karena itu penelitian ini bertujuan untuk menghasilkan suatu aplikasi berbasis short message service untuk membantu penguatan surveilans gizi di lapangan. Penelitian dilakukan pada bulan Maret-November 2013 di Puskesmas Banguntapan II. Subjek penelitian adalah bidan dan kader posyandu di wilayah ini. Aplikasi yang dibangun meliputi: bagian antar muka yang ditanam di handphone pengguna dan bagian server. Data selanjutnya disimpan ke dalam database di puskesmas untuk bahan laporan lebih lanjut. Dengan implementasi aplikasi ini diharapkan surveilans gizi, khususnya deteksi kasus balita gizi buruk, berjalan lebih cepat, akurat, lengkap, dan berkesinambungan sehingga dapat dilakukan penanganan yang segera dan adekuat.
\end{abstract}

Kata Kunci: sistem informasi bergerak, surveilans gizi, gizi buruk

\section{Pendahuluan}

Saat ini gizi buruk masih menjadi salah satu masalah kesehatan utama di Kabupaten Bantul. Gambar 1 menunjukkan bahwa angka gizi buruk balita di Kabupaten Bantul dari tahun 2006 s.d. 2011 cenderung menurun. Angka tersebut juga sudah berada di bawah target nasional yang besarnya 5\%, serta target Daerah Istimewa Yogyakarta (DIY) yang besarnya 2\%. Meskipun demikian, angka tersebut masih belum mencapai target Bantul yang besarnya $0,32 \%$. Gizi buruk pada anak balita dapat menimbulkan beberapa masalah kesehatan lainnya. Masalah tersebut antara lain: gangguan pertumbuhan, turunnya daya tahan tubuh balita sehingga balita lebih rentan menderita sakit infeksi, gangguan perkembangan kognitif, kelemahan, peningkatan 
risiko penyakit kronik di kemudian hari, serta sukar sembuhnya cedera/luka dan trauma yang ada. Sebagai akibat lebih lanjut adalah meningkatnya risiko kematian balita (Barasi, 2007).

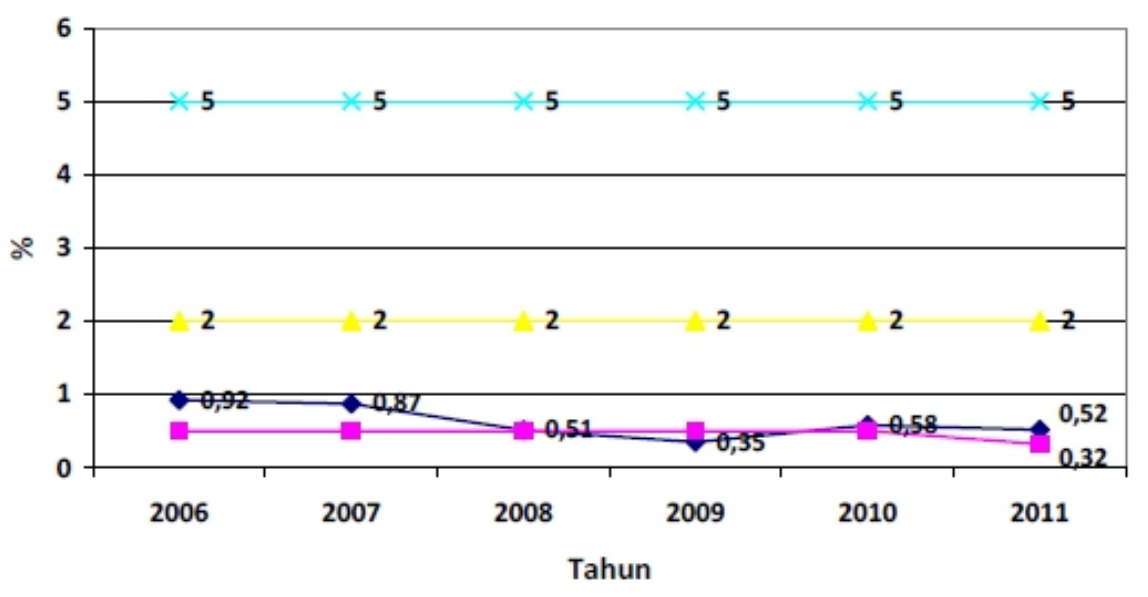

- Balita Gizi Buruk —-Target Bantul $\longrightarrow$ Target DIY $\longrightarrow$ Target Nasional

\section{Gambar 1. Angka Gizi Buruk Balita di Kabupaten Bantul Tahun 2006 s.d 2011 (Dinas Kesehatan Kabupaten Bantul, 2012)}

Saat ini Dinas Kesehatan Kabupaten Bantul dan Pemerintah Kabupaten Bantul telah berupaya keras untuk mengatasi permasalahan gizi buruk ini. Selain dengan program pemberian makanan tambahan (PMT) bagi balita gizi buruk, upaya lainnya adalah melalui Program Desa Bebas 4 Masalah Kesehatan (DBMK) Plus, yaitu: kematian ibu, kematian bayi, demam berdarah Dengue (DBD), gizi buruk, plus tuberkulosis (TB), sejak tahun 2006. Indikator keberhasilan program ini di antaranya adalah: tidak adanya kasus kematian ibu, kematian bayi, penderita DBD dan gizi buruk, serta penemuan penderita TB oleh masyarakat di suatu wilayah desa (Dinas Kesehatan Kabupaten Bantul, 2010a). Desa yang berhasil dalam program ini akan mendapatkan reward berupa uang pembinaan dari Pemerintah Kabupaten Bantul.

Studi pendahuluan yang dilakukan di Puskesmas Banguntapan II menunjukkan bahwa selain angka gizi buruk yang masih tinggi, kegiatan surveilans gizi juga belum berjalan optimal. Kegiatan pengumpulan data status gizi balita dan kasus balita gizi buruk di masing-masing posyandu serta pelaporannya ke puskesmas masih dilakukan secara manual oleh kader posyandu. Data tersebut selanjutnya direkap oleh bidan yang bertugas secara manual ke dalam form baku dari Dinas Kesehatan Kabupaten Bantul. Informasi yang ada selanjutnya disebarluaskan kepada para pihak yang berkepentingan. Dengan metode manual tersebut kegiatan surveilans gizi, khususnya deteksi kasus balita gizi buruk, menjadi kurang cepat.

Mengingat besarnya masalah yang ditimbulkan akibat gizi buruk pada balita, selain diperlukan penanganan yang adekuat juga diperlukan penguatan sistem surveilans gizi yang telah ada. Di antara seluruh kegiatan surveilans, kegiatan yang perlu dikuatkan di tingkat puskesmas terutama berupa: pengumpulan data, pengolahan dan penyajian data, analisis dan interpretasi data, pelaporan, dan penyebarluasan informasi. Terkait hal tersebut maka diperlukan aplikasi teknologi informasi dan komunikasi (TIK) untuk memperkuat pelaksanaan surveilans gizi yang telah berjalan. Dengan aplikasi ini diharapkan surveilans gizi, khususnya deteksi kasus balita gizi buruk, bisa berjalan lebih cepat, akurat, lengkap, dan berkesinambungan sehingga dapat dilakukan upaya penanganan yang sesuai dan segera.

Saat ini TIK berupa perangkat komputer dan jaringan internet belum dimiliki di setiap posyandu di wilayah Puskesmas Banguntapan II. Sehingga tidak memungkinkan untuk menyimpan data digital dengan menggunakan perangkat komputer. Upaya untuk mengusahakan ke arah sana pun sepertinya tidak begitu mudah, karena memang secara operasional setiap 
posyandu hanya beroperasi sebulan sekali. Meskipun demikian, para kader posyandu umumnya telah memiliki perangkat handphone dan biasa berkomunikasi dengan pihak puskesmas dengan perangkat tersebut. Karenanya aplikasi TIK yang dimungkinkan adalah sistem informasi bergerak yang berbasis short message service (SMS) dari handphone (SMS gateway). Oleh karena itu, penelitian ini bertujuan untuk menghasilkan suatu aplikasi berbasis SMS untuk membantu optimalisasi pelaksanaan surveilans gizi, khususnya deteksi kasus balita gizi buruk, di lapangan.

Penggunaan perangkat handphone untuk menyimpan dan mengirim data menjadi salah satu solusi karena dapat menjangkau hampir semua lapisan masyarakat. Data yang akan dihimpun dari sumber, yaitu kader Posyandu akan sangat penting. Karena data tersebut dapat menjadi data dasar untuk pengolahan data balita di tingkat berikutnya.

\section{Tinjauan Pustaka}

\section{1. Gizi Buruk}

Gizi buruk didefinisikan oleh World Health Organization (WHO) sebagai terdapatnya edema pada kedua kaki atau adanya severe wasting $(\mathrm{BB} / \mathrm{TB}<70 \%$ atau $<-3$ standard deviasi atau SD) atau adanya gejala klinis gizi buruk, berupa: kwashiorkor, marasmus, atau marasmikkwashiorkor pada anak. Anak didiagnosis gizi buruk apabila (WHO, 2005) : (1) BB/TB < -3 SD atau $<70 \%$ dari median (marasmus). (2) Edema pada kedua punggung kaki sampai seluruh tubuh (kwashiorkor: $\mathrm{BB} / \mathrm{TB}>-3 \mathrm{SD}$ atau marasmik kwashiorkor: $\mathrm{BB} / \mathrm{TB}<-3 \mathrm{SD}$ )

Di Indonesia, data balita gizi buruk terutama diperoleh dari hasil kegiatan penimbangan balita yang dilaksanakan di posyandu setiap bulannya. Data tersebut dicatat di dalam Kartu Menuju Sehat (KMS) balita dan selanjutnya dilaporkan oleh kader posyandu ke Unit Kesehatan Ibu dan Anak (KIA) di puskesmas yang membawahi. Data juga dapat diperoleh secara insidental dari hasil survei gizi atau penemuan pemeriksaan penderita di klinik. Pendataan, pelaporan, dan pengelolaan gizi buruk di puskesmas selanjutnya dikoordinasi oleh petugas (bidan) di Unit KIA bekerja sama dengan Unit Gizi puskesmas.

\subsection{Sistem Surveilans}

Menurut Centers for Disease Control and Prevention (CDC) dalam Gregg (2002) surveilans kesehatan masyarakat atau sering disebut juga surveilans epidemiologi adalah proses pengumpulan, analisis, dan interpretasi data yang outcome-spesific secara sistematik dan terusmenerus yang digunakan untuk perencanaan, implementasi, dan evaluasi praktik kesehatan masyarakat, yang terintegrasi dengan diseminasi data secara rutin kepada pihak-pihak yang membutuhkan. Berdasarkan Keputusan Menteri Kesehatan RI Nomor 1116 tahun 2003 sistem surveilans epidemiologi didefinisikan sebagai tatanan prosedur penyelenggaraan surveilans epidemiologi yang terintegrasi antara unit-unit penyelenggara surveilans dengan laboratorium, sumber-sumber data, pusat penelitian, pusat kajian dan penyelenggara program kesehatan, meliputi tata hubungan surveilans epidemiologi antar wilayah kabupaten/kota, provinsi dan pusat.

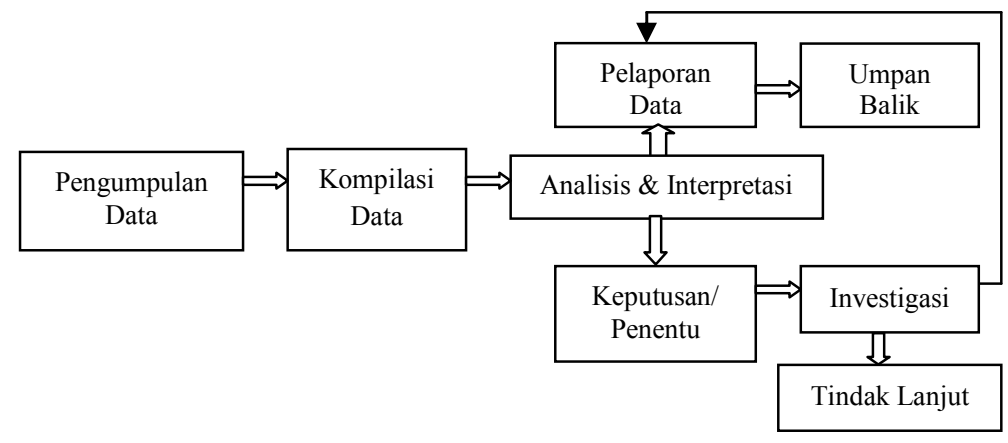

Gambar 2. Alur Surveilans Epidemiologi (Hidajah \& Hargono, 2006) 
Tujuan dari surveilans epidemiologi adalah untuk menilai status kesehatan masyarakat, menetapkan prioritas kesehatan masyarakat, evaluasi program, dan menyelenggarakan riset (Teutsch \& Churchill, 2000). Kegiatan surveilans epidemiologi terdiri atas komponenkomponen utama yaitu pengumpulan data, kompilasi (pengolahan dan penyajian) data, analisis dan interpretasi data, pelaporan, penyebarluasan informasi, dan umpan balik (Hidajah \& Hargono, 2006) dengan alur yang ditunjukkan dalam Gambar 2.

\subsection{Sistem Informasi Bergerak}

Sejauh ini komunikasi yang dilakukan di daerah pedesaan adalah dengan menggunakan perangkat handphone. Semakin murah dan mudahnya sarana ini digunakan menjadi alternatif yang cukup baik untuk melakukan komunikasi. Bahkan para provider berlomba untuk memasang base transceiver station (BTS) di desa-desa. Hal ini tentu saja menguntungkan masyarakat, apalagi daerah pegunungan yang tidak memungkinkan tersedia sarana telepon kabel karena area yang cukup luas dan jauh sehingga biayanya sangat mahal.

Keunggulan sistem informasi bergerak tersebut mendorong dikembangkannya implementasi sistem ini pada pelayanana kesehatan masyarakat. Sebagai contoh, pada musim panas tahun 2008, jaringan SMS diterapkan di Rumah Sakit St. Gabriel di pedesaan Malawi. Rumah sakit ini melayani seperempat juta orang, tersebar di seluruh daerah jangkauan radius 100 mil. Terdapat 600 pekerja kesehatan masyarakat untuk melayani sebagai relawan kesehatan di desa mereka. Terputus dari pelayanan rumah sakit dan sumber daya, kemampuan pekerja kesehatan untuk membantu pasien terbatas. Rumah sakit, klinik, dan organisasi dihadapkan pada tantangan penanganan kesehatan pedesaan, yaitu jarak dan kondisi yang terisolasi. Oleh karena itu, ditetapkan untuk mendapatkan keuntungan dari jaringan SMS berbiaya rendah. Dengan SMS dapat dihubungkan link yang hilang antara rumah sakit dan pekerja lapangan, pasien, anggota kelompok pendukung, atau pekerja kesehatan di desa masing-masing.

\section{Metode Penelitian}

Penelitian dilaksanakan di Puskesmas Banguntapan II, Kabupaten Bantul, sejak bulan Maret-November 2013. Puskesmas ini dipilih karena selain data tahun 2011 menunjukkan Kecamatan Banguntapan menduduki peringkat pertama jumlah balita gizi buruk, juga karena puskesmas ini saat ini sedang giat-giatnya mengembangkan aplikasi TIK dalam pelayanannya sehari-hari. Subjek penelitian adalah bidan Puskesmas Banguntapan II dan kader posyandu di wilayah Puskesmas Banguntapan II. Penelitian dilakukan dengan tahapan: (1) analisis dan pengumpulan data, (2) pembuatan desain sistem, dan (3) implementasi sistem.

Pada tahap analisis dan pengumpulan data, sebagai langkah awal dilakukan analisis kebutuhan calon pengguna sistem dan pengumpulan data dengan metode observasi di lapangan serta focus group discussion (FGD) dengan bidan puskesmas dan kader posyandu. Analisis tersebut mencakup: analisis kebutuhan informasi bagi bidan dan kader posyandu, analisis kebutuhan pembangunan sistem, dan analisis kebutuhan sarana prasarana sistem. Data yang dikumpulkan meliputi data seluruh posyandu yang ada di wilayah Puskesmas Banguntapan II, data kader posyandu, data balita dan ibunya yang terdaftar di masing-masing posyandu, data kegiatan posyandu, serta data lain yang terkait. Data ini selanjutnya diolah menjadi data yang sesuai dengan aplikasi dan desain database yang akan dibangun.

Pada tahap pembuatan desain sistem, sistem yang dibangun terdiri dari tiga bagian. Bagian pertama adalah pembuatan aplikasi untuk antar muka dengan pengguna. Aplikasi ini dimasukkan di handphone kader posyandu yang ditunjuk untuk merekam data balita dan hasil penimbangannya. Spesifikasi handphone yang dibutuhkan untuk aplikasi ini adalah yang memiliki perangkat Java. Data kemudian dikirimkan ke server melalui SMS. Bagian kedua adalah pembuatan database server. Bagian ketiga adalah pembangunan database yang digunakan untuk penyimpanan data balita dan status gizinya di puskesmas. Selain pembuatan desain sistem, juga dibuat desain format komunikasi. Komunikasi yang dilakukan oleh bidan dan kader posyandu adalah komunikasi dengan server. Untuk itu desain format komunikasi 
harus dibuat agar bidan dan kader posyandu dapat mengirimkan format komunikasi yang benar dan dikenali oleh server.

Pada tahap implementasi sistem, setelah sistem terbangun dilakukan implementasi aplikasi SMS gateway untuk menerima dan merespon SMS dari pengguna. Untuk implementasi sistem yang baru diperlukan data awal yang dimigrasi dari data yang berasal dari sistem yang sudah ada. Sistem SMS gateway sendiri secara umum sama dengan sistem SMS yang berlaku untuk SMS dari handphone ke handphone. Dalam hal ini, bedanya adalah satu sisi dari handphone terhubung ke server komputer. Sistem kemudian akan menerima data yang masuk untuk diolah. Selanjutnya, respon dikirim kembali dalam bentuk SMS ke handphone tersebut. Di sisi server, dibangun antar muka untuk sistem berbasis $S M S$ ini dengan database. Tujuannya agar informasi yang ada dapat diolah dan disimpan ke dalam database. Setelah semua siap dilakukan uji coba implementasi sistem pada bidan dan kader posyandu.

\section{Pengujian dan Pembahasan}

\subsection{Prototipe software yang dijalankan di handphone}

Prototipe software sistem informasi bergerak yang dihasilkan dalam penelitian ini dinamakan "Sistem Informasi Bidan Desa" (SIMBIDES). Software ini ditanamkan ke dalam handphone kader posyandu atau bidan yang telah ditunjuk sebagai operator sistem di posyandunya masing-masing. Kader tersebut bertugas memasukkan data balita dan hasil pengukuran BB (penimbangan) dan TB yang dilakukan di posyandu. Melalui sistem SMS gateway, data tersebut akan masuk ke database yang ada di puskesmas.

\subsection{Rancangan diagram kelas di handphone}

Setelah prototipe software dirancang, selanjutnya dibuat rancangan diagram kelas di handphone. Rancangan diagram kelas SIMBIDES disajikan dalam Gambar 3.

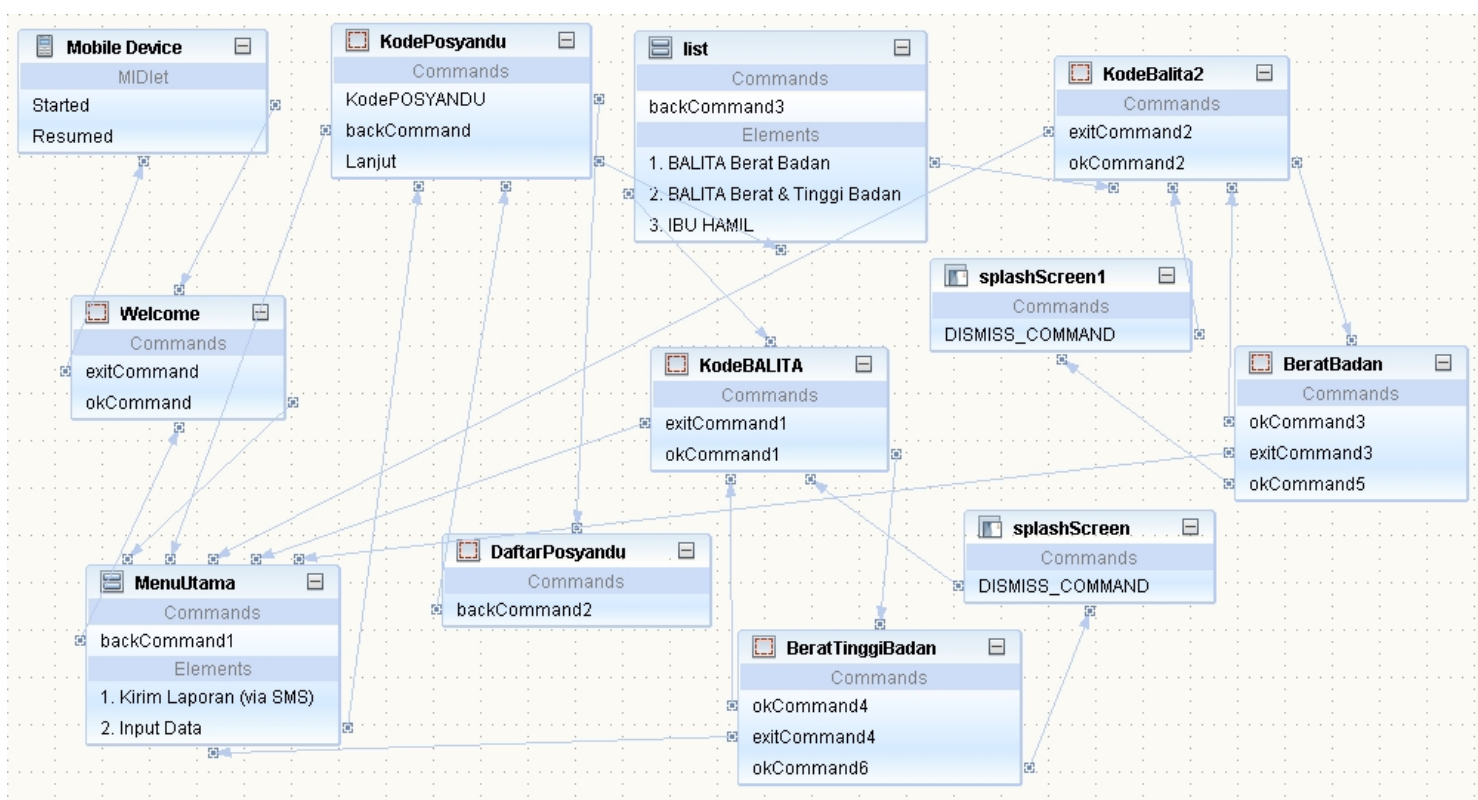

Gambar 3. Diagram Kelas SIMBIDES

\subsection{Tampilan menu di handphone}

Tampilan ini dibuat dengan tujuan untuk mempermudah bidan dan kader posyandu dalam memasukkan data kegiatan posyandu. Pada Gambar 4 menunjukkan tampilan awal dari aplikasi SIMBIDES, yaitu Sistem Informasi Bidan Desa dan tampilan untuk memasukkan data kode posyandu. Kode ini akan digunakan untuk membantu aplikasi membuka file data untuk posyandu dengan extensi txt (misalnya P001.txt) yang berisi daftar nama balita terdiri dari: 
kodeBalita, namaBalita, kodelbu, namaIbu. Selanjutnya data pada file tersebut dibaca dan disalin ke dalam format tabel seperti terlihat pada Gambar 5.

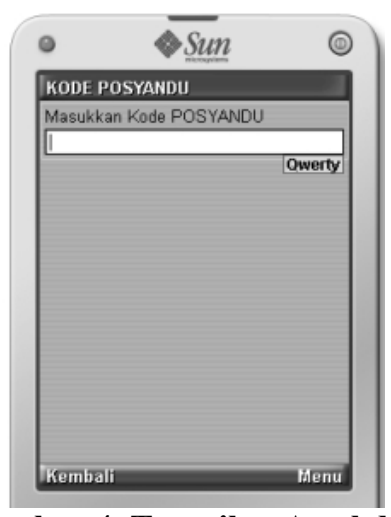

Gambar 4. Tampilan Awal dan Pilihan Cara Input

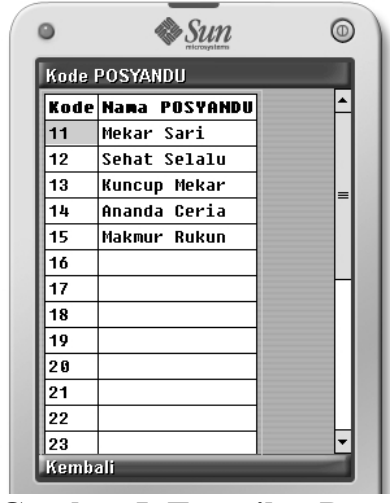

Gambar 5. Tampilan Data Balita Pada SIMBIDES

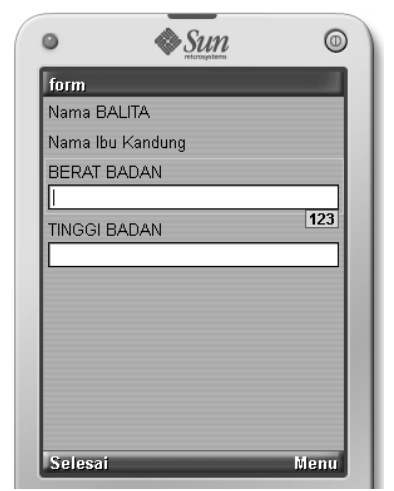

Gambar 6. Tampilan Isian Data Balita

Gambar 6 adalah tampilan untuk data identitas balita. Untuk memudahkan pemasukan data, maka telah dimasukkan data identitas balita yang saat ini ada di masing-masing posyandu beserta kodenya masing-masing. Apabila balita yang dimaksud belum terdata maka harus dibuatkan dulu isian datanya. Isian untuk data balita baru dimasukkan dari aplikasi yang ada di puskesmas. Setelah memilih salah satu balita, maka akan muncul data balita tersebut. Setelah dinyatakan benar, bidan atau kader dapat memasukkan data hasil pengukuran BB dan/atau TB balita, seperti tampak pada Gambar 6. Semua data balita yang sudah diisi akan disimpan dalan file dengan nama laporan.txt. File ini yang dikirim ke server melalui SMS.

\subsection{Rancangan database}

Data yang sudah dikoleksi di dalam handphone atau data yang dikirim via SMS harus disimpan dalam database. Rancangan database yang dibuat (data ibu balita, data balita, dan data tindakan terhadap balita) ditampilkan dalam Tabel 1.

Tabel 1. Rancangan database

\begin{tabular}{ll}
\hline \multicolumn{1}{c}{ Data Ibu Balita } & \multicolumn{1}{c}{ Tipe } \\
\hline IdIbu & Char \\
\hline Nama Ibu & Varchar \\
\hline Alamat & Varchar \\
\hline Dusun & Varchar \\
\hline Desa & Varchar \\
\hline Kecamatan & Varchar \\
\hline Kabupaten & Varchar \\
\hline Propinsi & Varchar \\
\hline Tanggal lahir & Date \\
\hline Nama Suami & Varchar \\
\hline Golongan Darah & Char \\
\hline Nomor telpon/HP & Varchar \\
\hline
\end{tabular}

\begin{tabular}{ll}
\multicolumn{1}{c}{ Data Balita } & \multicolumn{1}{c}{ Nama Field } \\
\hline IdAnak & Char \\
\hline Nama Anak & Varchar \\
\hline Jenis Kelamin & Varchar \\
\hline Tanggal Lahir & Date \\
\hline Jam Lahir & Time \\
\hline Berat badan & Int \\
\hline Panjang & Int \\
\hline Keadaan Lahir & Varchar \\
\hline IdIbu & Char \\
\hline Jenis Kelahiran & Varchar \\
\hline
\end{tabular}

\begin{tabular}{ll}
\multicolumn{1}{c}{ Tindakan terhadap } & Balita \\
\hline IdAnak Field & \multicolumn{1}{c}{ Tipe } \\
\hline Tanggal Periksa & Char \\
\hline Berat Badan & Date \\
\hline Tinggi Badan & Int \\
\hline Vitamin & Varchar \\
\hline Tindakan lainnya & Varchar
\end{tabular}

Tabel Tindakan terhadap Balita digunakan untuk menyimpan tindakan terhadap balita setiap kali pemeriksaan di posyandu. Selain tindakan berupa pengukuran BB dan TB, juga terdapat tindakan pemberian vitamin A pada balita setiap bulan Februari dan Agustus. Karena ini juga terkait upaya perbaikan gizi, maka format data ini juga disediakan ke dalam tabel ini. Tabel ini ke depannya akan berisi data pemeriksaan balita dari waktu ke waktu. Dengan 
demikian akan didapatkan data kohort masing-masing balita di setiap posyandu yang bersangkutan.

\subsection{Pembuatan Laporan}

Koleksi data yang sudah dihimpun, baik dari kiriman aplikasi SIMBIDES yang ada di handphone maupun dari SMS yang tersimpan di database, dapat diolah lebih lanjut dan dijadikan bahan untuk pembuatan laporan program. Dalam hal ini, data hasil penimbangan bayi dan balita di masing-masing posyandu dicatatkan pada form "Data Hasil Penimbangan" seperti terlihat pada Gambar 7.

\section{DATA HASIL PENIMBANGAN}

\begin{tabular}{|c|c|c|c|c|c|c|c|c|c|c|c|c|}
\hline \multicolumn{13}{|c|}{ Bulan Periksa : 8 / 2013} \\
\hline \multicolumn{13}{|c|}{ Nama Puskesmas : BANGUNTAPAN II } \\
\hline \multicolumn{13}{|c|}{ Nama Posyandu : Kembang Harapan } \\
\hline \multicolumn{13}{|c|}{ Dusun $\quad$ : Krobokan } \\
\hline \multicolumn{13}{|c|}{ Desa / Kelurahan : TAMANAN } \\
\hline \multirow[b]{2}{*}{ No } & \multirow[b]{2}{*}{ Nama Anak } & \multicolumn{2}{|c|}{ Sex } & \multirow[b]{2}{*}{ Nama Orang Tua } & \multirow[b]{2}{*}{ Alamat } & \multirow{2}{*}{\begin{tabular}{|l} 
BB \\
$(\mathrm{Kg})$
\end{tabular}} & \multirow{2}{*}{$\begin{array}{l}\text { TB } \\
(\mathrm{cm})\end{array}$} & \multirow{2}{*}{$\begin{array}{l}\mathrm{LL} \\
(\mathrm{cm})\end{array}$} & \multirow[b]{2}{*}{ Tgl. Lahir } & \multirow[b]{2}{*}{ Tgl. Timbang } & \multirow{2}{*}{$\begin{array}{l}\text { Umur } \\
\text { (bln) }\end{array}$} & Status Gizi \\
\hline & & & & & & & & & & & & $\mathrm{BBU} \mid \begin{array}{l}\mathrm{PBU} \\
\mathrm{TB} / 2\end{array}$ \\
\hline 1 & Latif & $\mathrm{L}$ & & Sulis & Krobokan & 20 & 114 & & 2010-10-01 & 2013-08-29 & 34 & \\
\hline 2 & Icha & & $\mathrm{P}$ & Yuni & Krobokan & 14 & 100 & & $2010-11-21$ & $2013-08-29$ & 33 & \\
\hline 3 & Singgih Mulya & $\operatorname{van} L$ & & Suharmi & Krobokan & 14 & 108 & & $2009-12-25$ & 2013-08-29 & 44 & \\
\hline
\end{tabular}

Gambar 7. Form Data Hasil Penimbangan Balita di Tingkat Posyandu

Gambar 7 menunjukkan bahwa selain data hasil penimbangan juga ditampilkan data identitas balita. Form tersebut selama ini diisi secara manual oleh kader posyandu atau bidan untuk kemudian dilaporkan ke puskesmas. Dengan aplikasi SIMBIDES pengisian form tersebut dilakukan secara terkomputerisasi. Hal ini penting peranannya bagi surveilans gizi, khususnya untuk deteksi kasus balita gizi buruk di puskesmas, karena akan diperoleh data yang sifatnya real time dan by name. Dengan demikian deteksi kasus bisa dilakukan lebih cepat dan akurat.

Selain laporan yang berupa data hasil penimbangan di tiap posyandu, juga dibutuhkan laporan yang berupa rekapitulasi status gizi bayi dan balita di masing-masing puskesmas. Selain untuk evaluasi capaian Program Gizi dan KIA puskesmas, laporan ini dibuat oleh puskesmas untuk keperluan pelaporan evaluasi keberhasilan Program DB4MK Plus, khususnya bidang gizi. Oleh karena itu sistem dirancang agar dapat memenuhi kebutuhan ini di lapangan. Sebagai gambaran, ditampilkan form Laporan Bulanan DBMK Gizi seperti terlihat pada Gambar 8.

LAPORAN BULANAN DBMK GIZI

\begin{tabular}{|c|c|c|c|c|c|c|c|c|c|c|c|c|c|}
\hline & \multirow{3}{*}{\multicolumn{2}{|c|}{ Uraian }} & \multicolumn{5}{|c|}{ Kelompok Umur } & & & & \multirow{2}{*}{\multicolumn{3}{|c|}{ JUMLAH }} \\
\hline No & & & \multicolumn{2}{|c|}{0 - 5 bulan } & \multicolumn{2}{|c|}{6 - 11 bulan } & \multicolumn{2}{|c|}{$12-23$ bulan } & \multicolumn{2}{|c|}{$24-59$ bulan } & & & \\
\hline & & & $\mathbf{L}$ & $\mathbf{P}$ & L & $\mathbf{P}$ & 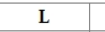 & $\mathbf{P}$ & L & $\mathbf{P}$ & \multicolumn{2}{|c|}{ L } & $\mathbf{P}$ \\
\hline 1 & \multicolumn{2}{|l|}{ Jumlah seluruh Balita (S) } & & & & & & & 2 & 1 & & 2 & 1 \\
\hline 2 & \multicolumn{2}{|l|}{ Jumlah Balita Ditimbang (D) } & & & & & & & 2 & 1 & & 2 & 1 \\
\hline 3 & \multicolumn{2}{|l|}{ Jumlah Balita yang naik berat badannya $(\mathrm{N})$} & & & & & & & & & & & \\
\hline 4 & \multicolumn{2}{|l|}{ Jumlah Balita yang tidak naik berat badannya $(\mathrm{T})$} & & & & & & & 2 & 1 & & 2 & 1 \\
\hline 5 & \multicolumn{2}{|l|}{ Jumlah Balita yang Bulan Kemarin tidak Menimbang (O) } & 1 & 1 & 2 & 2 & 1 & 2 & 4 & 2 & & 8 & 7 \\
\hline 6 & \multicolumn{2}{|l|}{ Jumlah Balita yang baru pertama ditimbang (B) } & & & & & & & 2 & & & 2 & \\
\hline 7 & \multicolumn{2}{|c|}{ Jumlah Balita yang tidak naik berat badannya 2 kali berturut-turut(T2) } & & & & & & & & & & & \\
\hline 8 & Jumlah Balita bawah garis merah (BGM) & & & & & & & & & & & & \\
\hline \multirow{2}{*}{ No } & \multirow{2}{*}{\multicolumn{2}{|c|}{ Uraian }} & \multicolumn{2}{|c|}{ Laki-laki } & \multicolumn{2}{|c|}{ Perempuan } & & & & & & & \\
\hline & & & Gakin & Tdk Gakin & Gakin & Tdk Gakin & & & & & & & \\
\hline 1 & \multicolumn{2}{|l|}{ Jumlah Bayi umur 6 bulan } & & & & & & & & & & & \\
\hline 2 & \multirow{2}{*}{\multicolumn{2}{|c|}{$\begin{array}{l}\text { Jumlah Bayi umur } 6 \text { bulan dengan asli eksklusif } \\
\text { Jumlah Anak umur } 7-24 \text { bulan }\end{array}$}} & & & & & & & & & & & \\
\hline 3 & & & & 2 & & 1 & & & & & & & \\
\hline \multirow[b]{2}{*}{ No } & \multirow{3}{*}{ Nama Bayi/Balita BGM } & \multirow{3}{*}{ L/P } & \multirow{3}{*}{ Tanggal Lahir } & & \multirow{2}{*}{\multicolumn{2}{|c|}{ Nama lbu }} & \multirow{3}{*}{ Tinggi Badan } & & \multirow{3}{*}{ Berat Badan } & \multirow{2}{*}{\multicolumn{2}{|c|}{ Status Gizi }} & & T-P \\
\hline & & & & & & & & & & & & Dapat & Tidak \\
\hline 1 & & & & & & & & & & & & & \\
\hline
\end{tabular}

Gambar 8. Form Laporan Bulanan DBMK Gizi 
Gambar 8 menunjukkan bahwa dengan rekapitulasi ini dapat diketahui jumlah seluruh balita yang ada di wilayah puskesmas, jumlah balita yang ditimbang, riwayat penimbangan dan kemajuan/kemunduran yang terjadi, serta data balita gizi buruk setiap bulannya. Status gizi balita ini penting untuk diketahui puskesmas untuk mendeteksi balita gizi buruk/bawah garis merah (BGM) di wilayahnya sehingga akan mempermudah dalam penanganan selanjutnya. Adapun bagi Program DB4MK Plus, laporan ini berguna untuk menilai berhasil atau tidaknya suatu desa dalam memberantas kasus balita gizi buruk di wilayahnya.

Seluruh rangkaian tahapan penelitian ini telah diujicobakan pada kader posyandu dan bidan desa di wilayah Puskesmas Banguntapan II. Dalam uji coba tersebut diperoleh masukan dari para pengguna. Masukan ini selanjutnya dijadikan bahan evaluasi bagi tim peneliti dan sebagai dasar unntuk perbaikan aplikasi ini. Implementasi TIK dalam kegiatan surveilans kesehatan merupakan suatu kebutuhan. Penelitian dari Dewi (2012) menunjukkan bahwa kurang optimalnya implementasi TIK dalam surveilans anemia pada kehamilan serta masih belum optimalnya ketrampilan penggunaan komputer dari para bidan di Unit KIA di 27 puskesmas di wilayah Dinas Kesehatan Kabupaten Bantul menyebabkan kegiatan pencatatan, pelaporan, pengolahan dan penyajian data menjadi kurang optimal. Akibat selanjutnya adalah analisis dan interpretasi data serta penyebarluasan informasi menjadi kurang optimal.

Implementasi TIK dalam sistem surveilans saat ini telah menjadi komitmen dari Kementerian Kesehatan Republik Indonesia (Kemenkes RI). Ini tampak dari rumusan strategi ke-3 dalam rangka pencapaian visi dan misi 2010-2014. Dalam upaya tersebut, Kemenkes RI telah menetapkan 4 strategi utama, yaitu: (1) menggerakkan dan memberdayakan masyarakat untuk hidup sehat, (2) meningkatkan akses masyarakat terhadap pelayanan kesehatan berkualitas, (3) meningkatkan sistem surveilans, monitoring dan informasi kesehatan, dan (4) meningkatkan pembiayaan kesehatan.

Bagi Dinas Kesehatan Kabupaten Bantul, hal ini juga telah menjadi komitmen (Dinas Kesehatan Kabupaten Bantul, 2010b). Komitmen ini tertuang dalam rumusan misi Dinas Kesehatan Kabupaten Bantul yang ke-7 yaitu: menyelenggarakan manajemen, informasi kesehatan dan penelitian di bidang kesehatan. Misi ini menjadi prioritas ke-7 pembangunan kesehatan di Kabupaten Bantul. Untuk mewujudkannya telah disusun strategi berupa peningkatan manajemen kesehatan yang akuntabel, transparan berdaya guna dan berhasil guna didukung oleh informasi kesehatan yang akurat (strategi ke-7) dan peningkatan upaya penelitian di bidang kesehatan melalui kemitraan (strategi ke-9).

Temuan permasalahan di lapangan serta dukungan komitmen dari Kemenkes RI maupun Dinas Kesehatan Kabupaten Bantul menunjukkan bahwa implementasi TIK dalam pelaksanaan sistem surveilans, monitoring dan informasi kesehatan merupakan suatu kebutuhan. Oleh karena itu, implementasi hasil penelitian ini pada surveilans gizi, khususnya deteksi kasus balita gizi buruk, diharapkan dapat memberi manfaat yang positif di lapangan.

\subsection{Sistem $S M S$}

Penggunaan handphone bersifat terbatas mengingat keterbatasan fitur handphone yang dimiliki bidan desa dan kader bidan desa. Mengingat keterbatasannya maka aplikasi pada handset tidak menyertakan adanya database. J2ME memungkinan penggunaan RMS sebagai database. Namun ditemui kendala pada saat pemindahan data dari komputer ke RMS. Untuk itu, agar terjadi konsistensi maka data balita dan data nama ibu disalin dari komputer ke handphone dengan cara transfer data berbentuk teks. Setiap posyandu memiliki file txt yang berisi nama balita dan nama ibu. File txt pada handphone dibaca oleh program J2ME untuk diambil kode balita dan diproses lebih lanjut sesuai kepentingan posyandu. Data baru yang berisi kode balita dan hasil pengukuran atau tindakan di posyandu kemudian disimpan didalam handphone dengan format txt. Program pengiriman SMS melakukan pembacaan data pada file txt tersebut dan selanjutnya dimasukkan sebagai badan pesan $S M S$ yang dikirimkan ke $S M S$ server di Puskesmas. Program SMS gateway di komputer Puskesmas yang menerima data SMS selanjutnya memproses untuk dimasukkan ke database (MySQL). Dari hasil FGD untuk 40 
Posyandu diperoleh data spesifikasi handphone yang mampu ditanam program $J 2 M E$ sebanyak enam buah handphone dengan spesifikasi handphone feature yang mendukung aplikasi Java Mobile. Sisanya merupakan handphone basic dengan kemampuan voice dan SMS. Pada prinsipnya, handphone digunakan untuk memasukkan data melalui format-format SMS yang sudah ditetapkan. Peran program Java adalah sebagai antarmuka yang memudahkan pengguna untuk mengisi melalui form-form yang disediakan dan selanjutnya secara series data akan disimpan melalui program J2ME menjadi data SMS series. Sinkronisasi data dilakukan melalui file txt dengan content yang berbeda untuk setiap POSYANDU tergantung pada anggota pada POSYANDU tersebut. Data POSYANDU ini disimpan pada file 001.txt untuk POSYANDU nomor 001 dengan isi file sebagai berikut:

001;Latif;Bu Nini

002;Icha;Bu Ninik

003;Haloona;Bu Ninik

File 001.txt ini diturunkan dari tabel Gambar 9. Update data pada handphone dilakukan dengan menyalin file hasil konversi database ke bentuk txt.

Data Anak
\begin{tabular}{|r|l|l|l|r|r|r|}
\hline Data Ibu & Posyandu & & \\
\hline IdAnak & NamaAnak & JenisKelamin & TanggalLahir & Idlbu & BeratBadanLahir & PanjangLahil ${ }^{\wedge}$ \\
\hline 1 & Latif & Laki-laki & $01 / 10 / 2010$ & 1 & 3 & 45 \\
\hline 2 & Icha & Perempuan & $21 / 11 / 2010$ & 2 & 3 & 45 \\
\hline 3 & Haloona & Perempuan & $21 / 11 / 2010$ & 2 & 3 & 45 \\
\hline 4 & Singgih Mulyawan & Laki-laki & $25 / 12 / 2009$ & 4 & 3 & 45 \\
\hline
\end{tabular}

Gambar 9. Tabel Data

Sedangkan format Pengiriman SMS adalah IdAnak, berat badan, tinggi badan untuk setiap anak. Contoh $S M S$ yang dikirim ke no server: 1;10;30;0\#2;15;35;1\#3;13;25;2\#. Contoh tersebut menunjukan ada tiga informasi data anak, setiap informasi seorang anak dipisahkan dengan tanda \# (kres). Untuk informasi Idanak, berat badan, tinggi badan dan vitamin setiap anak, dipisahkan dengan tanda; (petik bintang). Untuk data pertama, angka 1 menunjukan IdAnak, angka 10 menunjukan berat badan, angka 30 menunjukan tinggi badan, angka 0 menunjukan bahwa anak tersebut belum mendapatkan vitamin.

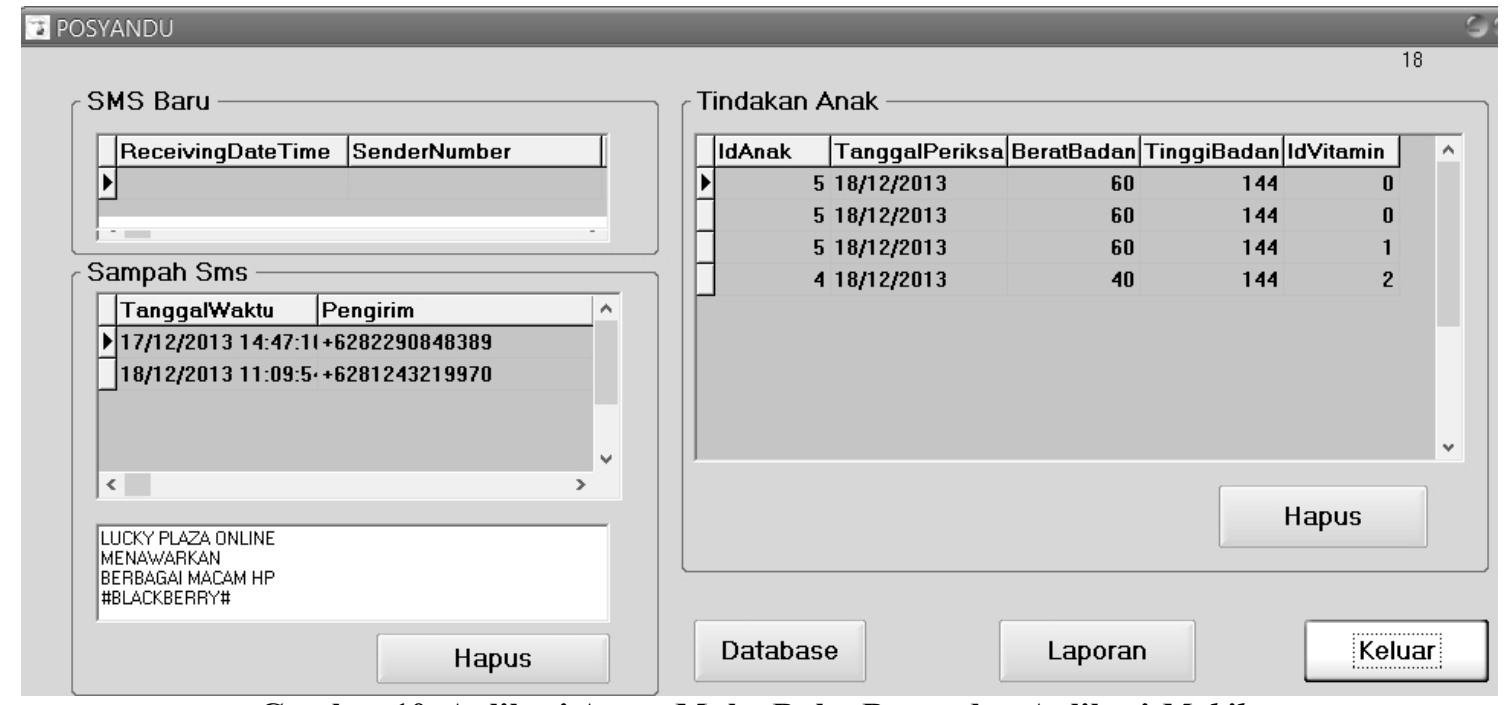

Gambar 10. Aplikasi Antar Muka Buku Bantu dan Aplikasi Mobile

Fokus implementasi handphone saat ini adalah pada penggunaan teknologi pemindahan data. Tiap bidan desa atau kader bidan desa dibekali dengan buku bantu yang digunakan pada 
saat aktifitas pencatatan di POSYANDU. Pada prosedur kerjanya, data dari buku bantu tersebut dilaporkan ke puskesmas yang selanjutnya dipindah ke program spreadsheet di PUSKESMAS.

Fungsi program SMS adalah memindah peran buku bantu menjadi aplikasi mobile dan secara otomatis akan dipindahkan ke aplikasi yang dibangun. Aplikasi ini ditunjukkan pada Gambar 10.

\section{Kesimpulan}

Dari penelitian ini dapat disimpulkan bahwa: (1) Bidan dapat menggunakan aplikasi SIMBIDES untuk mengirimkan kegiatan di POSYANDU dalam format digital dan langsung terumpan ke server database yang ditetapkan. (2) Dengan memanfaatkan tabel dalam format txt yang disalin dari komputer server ke peranti bergerak (handphone) dan menu-menu yang disediakan dalam peranti bergerak, maka format pengiriman dapat disusun dengan pasti sehingga kesalahan pengetikan karena human factor dapat diminimalisir.

\section{Referensi}

Barasi, M.E. 2007. At a Glance Imu Gizi, Terjemahan oleh: Halim, H. 2009. Jakarta: Penerbit Erlangga

Deitel Deitel, 2003. Java Web Service for Experienced Programmers, Prentice Hall, New Jersey.

Dewi, S.K. 2012. Evaluasi dan Implementasi Sistem Surveilans Anemia pada Kehamilan di Kabupaten Bantul Tahun 2010. Laporan Penelitian Lapangan tidak diterbitkan. Yogyakarta: Magister FETP-IKM FK UGM.

Dinas Kesehatan Kabupaten Bantul. 2010a. Info Desa Bebas 4 Masalah Kesehatan (DB4MK) Plus TB Tahun 2010, (Online), (http://www.dinkes.bantulkab.go.id, diakses 13 November 2013).

Dinas Kesehatan Kabupaten Bantul. 2010b. Rencana Strategis Dinas Kesehatan Kabupaten Bantul Tahun 2011-2015. Bantul: Dinas Kesehatan Kabupaten bantul.

Dinas Kesehatan Kabupaten Bantul. 2012. Profil Kesehatan Kabupaten Bantul Tahun 2012. Bantul: Dinas Kesehatan Kabupaten Bantul.

Gregg, M.G. 2002. Field Epidemiology, $2^{\text {nd }}$ edition, New York: Oxford University Press.

Hidajah, A.C, Hargono, A, 2006, Bahan Ajar Surveilans Epidemiologi, Edisi Revisi, Bagian Epidemiologi, Fakultas Kesehatan Masyarakat, Surabaya: Universitas Airlangga.

Jeni Center, 2007. Pemrograman Mobile, Jeni Center VEDC, Malang.

Menteri Kesehatan RI. 2003. Keputusan Menteri Kesehatan RI Nomor 1116 Tahun 2003. Jakarta: Departemen Kesehatan RI.

Michael Juntao Yuan, 2, 2004. Enterprise J2ME, Developing Mobile Java Application, Prentice Hall, New Jersey.

Richard Monson-Haefel, 2004, Enterprise Java Beans, O'Reilly, United States of America.

Teutsch, M.S, Churchill, R.E. 2000. Principles and Practice of Public Health Surveillance. $2^{\text {nd }}$ edition. New York: Oxford University Press.

WHO. 2005. Buku Saku Pelayanan Kesehatan Anak di Rumah Sakit: pedoman bagi rumah sakit rujukan tingkat pertama di kabupaten/kota. Terjemahan oleh: WHO Indonesia. 2009. Cetakan I. Jakarta: WHO Indonesia. 